\title{
Determinants of Maternal Satisfaction with Spinal Anaesthesia Care for Caesarian Delivery at the Kisumu County Hospital
}

\author{
*Morris Senghor Shisanya ${ }^{1}$, Everlyne Nyanchera Morema², \\ ${ }^{I}$ Department Of Community Health Nursing, School Of Nursing and Midwifery, Great Lakes University Of Kisumu (GLUK) \\ ${ }^{2}$ Department Of Community Health Nursing, School Of Nursing and Midwifery, Masinde Muliro University Of Science And \\ Technology (MMUST) \\ *Corresponding author
}

\begin{abstract}
Elective and emergency caesarean sections are increasing in the low income countries. Over the last fifteen years or so, spinal anaesthesia has been gradually escalated in Kenyan Hospitals. In Kisumu County Hospital (KCH), the cases of caesarean sections done under spinal anaesthesia have increased tremendously from one in every ten to seven in every ten cases in a span of 7 years. Despite documented safety for the procedure, complications can highly influence the mother's perception of quality of care. This study was therefore undertaken to evaluate patient satisfaction after spinal anaesthesia for caesarean section. A crosssectional study of patients who underwent caesarean section under spinal anaesthesia in the operating rooms of $\mathrm{KCH}$ was conducted. Post-operative survey of patients on the day after surgery was conducted by collecting pre-operative and intra-operative data on a structured questionnaire. Post-operative data, including satisfaction and understanding the anaesthetist's explanation regarding anaesthesia and satisfaction in receiving spinal anaesthesia were inquired by trained data personnel. A total of 99 pregnant patients, with age ranging from 17 to 40 years, were surveyed: Overall, 85 (85\%) of the mothers interviewed were satisfied and 15 (15\%) were dissatisfied the anaesthesia care they received. Income range (OR: 23.1; 95\% CI: 2.77-192; $P<0.001)$ and marital status (OR: 4.42; 95\% CI 1.32-14.9; $P<0.011)$ were significant demographic determinant of satisfaction with maternal satisfaction with anaesthesia care. Neonatal outcomes were also demonstrated to be associated with satisfaction were; neonate's birth weight (OR: 3.29; 95\% CI: 1.01-10.71; P:0.04) and APGAR score at 10 minutes (OR:4.74; 95\% CI: 1.24-18.03; P:0.02). In comparison to studies elsewhere, maternal satisfaction in the surveyed population was low. Structured communication by anaesthesia team, exceptional clinical skill of the anaesthesia practitioners and prevention of side effects might improve patient satisfaction.
\end{abstract}

\section{Background}

Global statistics indicate that nearly 213 million women conceive and deliver yearly. Approximately 18.5 million deliver through caesarean section (WHO, 2012). In Kenya about fifteen years ago, all caesarean sections were performed under general anaesthesia. As expected, there was a large proportion of maternal and neonatal morbidity attributable mainly to difficult or failed endotracheal intubations and aspiration of regurgitated gastric contents. In keeping with current obstetric anaesthesia guidelines, it was recommended that regional anaesthesia for caesarean section be introduced in our operating institutions. Another factor that has encouraged the introduction of spinal anaesthesia for caesarean section in Kenya, is its lower cost as compared to general anaesthesia (Casey, 2000). The last fifteen years or so have seen spinal anaesthesia gradually escalated in Kenyan hospitals to become the choice anaesthesia procedure for caesarean delivery. In Kisumu County Hospital $(\mathrm{KCH})$, the cases of caesarean sections done under spinal anaesthesia have increased tremendously from one in every ten to seven in every ten cases in a span of 7 years.

As much as spinal anaesthesia is easy to administer there are complications that accompany it for both the mother and the neonate. These complications can severely impact on maternal satisfaction with care.There are no definitive protocols that have been found to totally eliminate the risks of maternal complications during and after caesarean section under spinal anaesthesia. It is, therefore, important to establish the level of client satisfaction with spinal anaesthesia which is one of the indicators of quality of care. Research studies conducted on maternal satisfaction vary, especially after caesarean section. Within the upper income countries, studies indicate higher rates of maternal satisfaction with healthcare delivery: South Australia, 86.1\%. Contrary to a research carried out in a low income country, satisfaction was between 2.4 and 21\%(Melese, Gebrehiwot, Bisetegne, \& Habte, 2014; South Australian Patient Evaluation of Health Services (PEHS), 2007). Low levels of maternal satisfaction have similarly been reported in other African Countries; $51.9 \%$ in South Africa Effective management of pain was the highest rated area of dissatisfaction with studies indicating $82 \%$ of mothers report dissatisfaction (Melese et al., 2014) 


\section{Methodology}

This was a cross-sectional study of patients who underwent caesarean section under spinal anaesthesia in the operating rooms of $\mathrm{KCH}$ was conducted between June and October 2016. A total of 99 patients were surveyed as calculated using Taro Yamane formula. Post-operative survey of patients on the day after surgery up to one month was conducted by collecting data on a structured questionnaire. Post-operative survey of patients on the day after surgery was conducted by collecting pre-operative and intra-operative data on a constructed questionnaire. Post-operative data, including satisfaction and understanding the anaesthetist's explanation regarding anaesthesia and satisfaction in receiving spinal anaesthesia were inquired by trained data personnel. Data analysis was done using SPSS version 21. Bivariate analysis was conducted on the data with chi-square statistics used to determine the homogeneity in proportions. Odd ratios and 95\% CI were used to show strength of association with $\mathrm{P}$ value used to show significance of the relationships.

\section{Results}

\section{Socio-demographic Characteristics of the respondents}

The table 1 below depicts a summary of the backdrop of socio-demographic aspects of the respondents. The respondents below 30 years of age were $71.7 \%$ with a mean age of 23.3 years and minimum and maximum age being 17 and 40 years respectively. Most of the respondents (56.6\%) had attained secondary and above level of education. Fifty three percent were from urban areas and $82 \%$ were married.

Table 1: Socio-demographic Characteristics of the Respondents

\begin{tabular}{|c|c|c|c|}
\hline Characteristic & Grouping & Frequency & Percent \\
\hline \multirow{4}{*}{ Age } & Below 30 & 71 & 71.7 \\
\hline & 30 and Above & 28 & 28.3 \\
\hline & Total & 99 & 100.0 \\
\hline & \multicolumn{3}{|c|}{$\mathrm{Av}=26.3, \mathrm{Mod}=20, \mathrm{SD}=6.3, \mathrm{Min}=17, \mathrm{Max}=40$} \\
\hline \multirow{5}{*}{ Education Level } & Did not School & 7 & 7.1 \\
\hline & Primary & 36 & 36.4 \\
\hline & Secondary & 41 & 41.4 \\
\hline & Tertiary & 15 & 15.2 \\
\hline & Total & 99 & 100.0 \\
\hline \multirow{3}{*}{ Residence Type } & Urban & 53 & 53.5 \\
\hline & Rural & 45 & 45.5 \\
\hline & Total & 98 & 99.0 \\
\hline \multirow{3}{*}{ Marital Status } & Not Married & 17 & 17.2 \\
\hline & Married & 82 & 82.8 \\
\hline & Total & 99 & 100.0 \\
\hline \multirow{5}{*}{ Employment } & Employed & 39 & 39.4 \\
\hline & Unemployed & 18 & 18.2 \\
\hline & Housewife & 33 & 33.3 \\
\hline & Farmer & 7 & 7.1 \\
\hline & Total & 97 & 98.0 \\
\hline \multirow{4}{*}{ Income Range } & Below 15000 & 20 & 20.2 \\
\hline & 15000 and Above & 24 & 24.2 \\
\hline & Total & 44 & 44.4 \\
\hline & \multicolumn{3}{|c|}{$\mathrm{Av}=16227, \mathrm{Mod}=10000, \mathrm{SD}=8696, \mathrm{Min}=5000, \mathrm{Max}=40000$} \\
\hline
\end{tabular}

\section{Determinants of Maternal Satisfaction with Spinal Anaesthesia Demographic Determinants of Maternal Satisfaction}

Table 2 presents the distribution of the demographic characteristics of the respondents and illustration of the maternal satisfaction with anaesthesia care. Levels of significance were assumed at $P<0.05$. Out of the total $(\mathrm{n}=99)$ interviewed $84(84.8 \%)$ were categorized as satisfied with anaesthesia care while $15(15.2 \%)$ were not satisfied. There was a significant relationship between marital status (OR: 4.42; 95\% CI 1.32-14.9; P<0.011) and income range (OR: 23.1; 95\% CI: 2.77-192; P<0.001) with maternal satisfaction with anaesthesia care.

The other demographic variables, maternal age, residence and employment status did not demonstrate significance in determining maternal satisfaction with anaesthesia care.

Table 2: Demographic determinants of maternal Satisfaction

\begin{tabular}{|l|l|l|l|l|l|l|}
\hline \multirow{2}{*}{$\begin{array}{l}\text { Demographic } \\
\text { Characteristic }\end{array}$} & Grouping Characteristic & \multicolumn{2}{|l|}{ Satisfaction With SA } & OR & 95\% CI & \multirow{2}{*}{ P Value } \\
\cline { 2 - 4 } & & Yes & No & & & \\
\hline \multirow{2}{*}{ Age Range } & Below 30 & $58(82)$ & $13(18)$ & 0.34 & $0.07-1.63$ & .163 \\
\cline { 2 - 4 } & 30 and Above & $26(93)$ & $2(7)$ & & & \\
\hline \multirow{2}{*}{ Residence Type } & Urban & $48(91)$ & $5(9)$ & 2.74 & $0.86-8.74$ & .080 \\
\cline { 2 - 4 } & Rural & $35(78)$ & $10(22)$ & & & \\
\hline Marital Status & Not Married & $11(65)$ & $6(35)$ & $\mathbf{4 . 4 2}$ & $\mathbf{1 . 3 2 - 1 4 . 9}$ & $\mathbf{. 0 1 1}$ \\
\hline
\end{tabular}


Determinant Maternal Satisfaction with Spinal Anaesthesia Care for Caeserian Delivery at the

\begin{tabular}{|l|l|l|l|l|l|l|}
\hline & Married & $73(89)$ & $9(11)$ & & & \\
\hline \multirow{2}{*}{ Employment } & Employed & $35(90)$ & $4(10)$ & 2.00 & $0.60-6.98$ & .245 \\
\cline { 2 - 4 } & Unemployed & $47(81)$ & $11(19)$ & & & \\
\hline \multirow{2}{*}{ Income Range } & 15000 and Above & $59(98)$ & $1(2)$ & $\mathbf{2 3 . 1}$ & $\mathbf{2 . 7 7 - 1 9 2}$ & $<\mathbf{0 . 0 0 1}$ \\
\cline { 2 - 4 } & Below 15000 & $23(72)$ & $9(28)$ & & & \\
\hline
\end{tabular}

\section{Parturition History and Maternal Satisfaction}

The table below describes maternal parturition history of the role of the characteristics in determining maternal satisfaction. Only two aspects of parturition history demonstrated significance in predicting maternal satisfaction; birth weight (OR: 3.29; 95\% CI: 1.01-1071; P<0.04;) and APGAR Score at 10 minutes (OR:4.74; 95\% CI: $1.24-18.03$; $\mathrm{P} 0.02)$. Gestation by time of parturition ( $\mathrm{P}=0.15)$, gravidity $(\mathrm{P}=0.21)$, sex of the baby $(\mathrm{P}=0.14)$, status of the baby $(\mathrm{P}=0.43)$, co-morbidity in pregnancy $(\mathrm{P}=0.97)$, and reason for the current caeserian section $(\mathrm{P}=0.46)$ did not demonstrate significance in relationship with maternal satisfaction with anaesthesia care.

Table 3: Parturition History and Maternal Satisfaction

\begin{tabular}{|c|c|c|c|c|c|c|}
\hline \multirow[t]{2}{*}{ Past Parturition History } & \multirow{2}{*}{$\begin{array}{l}\text { Grouping } \\
\text { Characteristics }\end{array}$} & \multicolumn{2}{|c|}{ Satisfaction With SA } & \multirow[t]{2}{*}{ OR } & \multirow[t]{2}{*}{$95 \%$ CI } & \multirow[t]{2}{*}{ P Value } \\
\hline & & Yes & No & & & \\
\hline \multirow[t]{2}{*}{ Gravida } & One & $25(78)$ & $7(22)$ & \multirow[t]{2}{*}{0.49} & \multirow[t]{2}{*}{$0.16-1.51$} & \multirow[t]{2}{*}{0.21} \\
\hline & More Than One & $58(88)$ & $8(12)$ & & & \\
\hline \multirow{2}{*}{$\begin{array}{l}\text { Gestation by time of } \\
\text { Parturition }\end{array}$} & 36 Weeks and Above & $64(82)$ & $14(18)$ & \multirow[t]{2}{*}{0.24} & \multirow[t]{2}{*}{$0.03-1.95$} & \multirow[t]{2}{*}{0.15} \\
\hline & Less than 36 Weeks & $19(95)$ & $1(5)$ & & & \\
\hline \multirow[t]{2}{*}{ Birth Weight } & 3000 and Above & $69(89)$ & $9(11)$ & \multirow[t]{2}{*}{3.29} & \multirow[t]{2}{*}{ 1.01-1071 } & \multirow[t]{2}{*}{0.04} \\
\hline & Less than 3000 & $14(70)$ & $6(10)$ & & & \\
\hline \multirow[t]{2}{*}{ APGAR at 10 Minutes } & 10 & $45(94)$ & $3(6)$ & \multirow[t]{2}{*}{4.74} & \multirow[t]{2}{*}{ 1.24-18.03 } & \multirow[t]{2}{*}{0.02} \\
\hline & Below 10 & $38(76)$ & $12(24)$ & & & \\
\hline \multirow[t]{2}{*}{ Sex of Baby } & Male & $44(80)$ & $11(20)$ & \multirow[t]{2}{*}{0.41} & \multirow[t]{2}{*}{$0.12-1.39$} & \multirow[t]{2}{*}{0.14} \\
\hline & Female & $39(91)$ & $4(9)$ & & & \\
\hline \multirow[t]{2}{*}{ Status of Baby } & Alive & 7786 & $13(14)$ & \multirow[t]{2}{*}{1.97} & \multirow[t]{2}{*}{$0.35-10.9$} & \multirow[t]{2}{*}{0.43} \\
\hline & Passed on & $6(75)$ & $2(25)$ & & & \\
\hline \multirow[t]{2}{*}{ Co-morbidity in Pregnancy } & Yes & $21(84)$ & $4(16)$ & \multirow[t]{2}{*}{0.98} & \multirow[t]{2}{*}{$0.28-3.41$} & \multirow[t]{2}{*}{0.97} \\
\hline & No & $59(84)$ & $11(16)$ & & & \\
\hline \multirow[t]{2}{*}{ Reason for Current CS } & Elective & $3(100)$ & $0(0)$ & \multirow[t]{2}{*}{1.19} & \multirow[t]{2}{*}{$1.01-1.30$} & 0.46 \\
\hline & Emergency & $80(84)$ & $15(16)$ & & & \\
\hline
\end{tabular}

\section{Past Anaesthesia Experience and Maternal Satisfaction}

On past anaesthesia experience, no aspect demonstrated significance in determining maternal satisfaction; had anaesthesia before (OR: 1.35 ; $95 \%$ CI: 0.45-4.08; P<0.59), types of anaesthesia the client had before (OR: $0.40 ; 95 \%$ CI: $0.41-9.38 ; \mathrm{P}<0.40)$ and complications following prior anaesthesia $(\mathrm{OR}: 2.65 ; 95 \%$ CI: $0.30-23.5 ; \mathrm{P}<0.37)$

Table4: Past Anaesthesia Experience and Maternal Satisfaction

\begin{tabular}{|l|l|l|l|l|l|l|}
\hline Past Anaesthesia Experience & Grouping & \multicolumn{2}{|l|}{ Satisfaction With SA } & OR & 95\% CI & \multirow{2}{*}{ P Value } \\
\cline { 2 - 4 } & Characteristics & Yes & No & & & \\
\hline \multirow{2}{*}{ Had Anaesthesia Before } & Yes & $51(86)$ & $8(14)$ & 1.35 & $0.45-4.08$ & 0.59 \\
\cline { 2 - 4 } & No & $33(83)$ & $7(17)$ & & & \\
\hline Anaesthesia Had Before & General & $12(80)$ & $3(20)$ & 1.95 & $0.41-9.38$ & 0.40 \\
\cline { 2 - 4 } & Spinal & $39(89)$ & $5(11)$ & & & \\
\hline $\begin{array}{l}\text { Complication from Prior } \\
\text { Anaesthesia }\end{array}$ & Yes & $14(93)$ & $1(7)$ & 2.65 & $0.30-23.5$ & 0.37 \\
\cline { 2 - 4 } & No & $37(84)$ & $7(16)$ & & & \\
\hline
\end{tabular}

\section{Perioperative Experience during the Current Delivery and Maternal Satisfaction}

Table 5 shows the relationship between of peri-operative aspects such as; experiencing intra-operative pain, having post operative backache, post operative nausea and vomiting, number of puncture attempts, being visited in the ward by the anaesthetist before the operation, procedure explained to the client before surgery and post operative visit by the anaesthetist. Post operative visit by the anaesthetist is the only aspect that demonstrated significance in determining maternal satisfaction with care provided.

Table5: Perioperative Experience during the Current Delivery and Maternal Satisfaction

\begin{tabular}{|l|l|l|l|l|l|l|}
\hline Peri-Operative aspects & Grouping & Satisfaction With SA & \multirow{2}{*}{ OR } & 95 \% CI & \multirow{2}{*}{ P Value } \\
\cline { 2 - 4 } & Characteristics & Yes & No & & & \\
\hline \multirow{2}{*}{ Intra-Operative Pain } & Yes & $12(100)$ & $0(0)$ & 1.21 & $1.10-1.33$ & 0.12 \\
\cline { 2 - 4 } & No & $72(83)$ & $15(17)$ & & & \\
\hline Post Operative Backache & Yes & $39(83)$ & $8(17)$ & 0.76 & $0.25-2.28$ & 0.62 \\
\cline { 2 - 4 } & No & $45(87)$ & $7(13)$ & & & \\
\hline
\end{tabular}


Determinant Maternal Satisfaction with Spinal Anaesthesia Care for Caeserian Delivery at the

\begin{tabular}{|c|c|c|c|c|c|c|}
\hline \multirow[t]{2}{*}{ Post Operative Nausea \& Vomiting } & Yes & $28(85)$ & $5(15)$ & \multirow[t]{2}{*}{1.00} & \multirow[t]{2}{*}{$0.31-3.21$} & \multirow[t]{2}{*}{1.00} \\
\hline & No & $56(85)$ & $10(15)$ & & & \\
\hline \multirow[t]{2}{*}{ Puncture Attempts } & $1-2$ & $40(87)$ & $6(13)$ & \multirow[t]{2}{*}{1.36} & \multirow[t]{2}{*}{$0.45-4.17$} & \multirow[t]{2}{*}{0.59} \\
\hline & $>2$ & 44 & 9 & & & \\
\hline \multirow{2}{*}{$\begin{array}{l}\text { Visited in Ward by Anaesthetist } \\
\text { Before CS }\end{array}$} & Yes & $7(70)$ & $3(30)$ & \multirow[t]{2}{*}{0.36} & \multirow[t]{2}{*}{$0.08-1.60$} & \multirow[t]{2}{*}{0.17} \\
\hline & No & $77(87)$ & $12(13)$ & & & \\
\hline \multirow{2}{*}{ Procedure Explained Before } & Yes & $26(84)$ & $5(16)$ & \multirow[t]{2}{*}{0.90} & \multirow[t]{2}{*}{$0.28-2.89$} & \multirow[t]{2}{*}{0.86} \\
\hline & No & $58(85)$ & $10(15)$ & & & \\
\hline \multirow{2}{*}{$\begin{array}{l}\text { Visited in Ward by Anaesthetist } \\
\text { After CS }\end{array}$} & Yes & $13(65)$ & $7(35)$ & \multirow[t]{2}{*}{0.21} & \multirow[t]{2}{*}{ 0.07-0.68 } & \multirow[t]{2}{*}{$\mathbf{0 . 0 0 6}$} \\
\hline & No & $71(90)$ & $8(10)$ & & & \\
\hline
\end{tabular}

\section{Discussion}

Elective and emergency caesarean sections are increasing in the low income countries (Stanton \& Holtz, 2006). The choice of anaesthesia has equally increasingly shifted from general to spinal anaesthesia. Spinal anaesthesia is relatively easy to perform, has lower risks and provides excellent operating conditions for caesarean section compared to general anaesthesia. It has been documented that women who undergo spinal anaesthesia for caesarian section have shorter hospital stay than general anaesthesia. The benefits of spinal over general anaesthesia cannot be overemphasized. Despite all the documented benefits of spinal anaesthesia versus general anaesthesia, patient satisfaction is the gold standard in assessing the quality care in anaesthesia practice (Van Campen et al., 1995)

Most studies report high satisfaction levels for spinal anaesthesia. The current study estimated maternal satisfaction at $85 \%$. Most of the reviewed studies had higher levels of satisfaction, between $90 \%$ and $100 \%$. Satisfaction rate can be overestimated because patients like to please service providers by giving the desired reply (Dharmalingam \& Ahmad Zainuddin, 2013; Rashad Siddiqi \& Syed Asadullah Jafri, 2009). The researcher for current study trained none care givers to administer the questionnaire thus reducing the client staff effect on the responses.

Satisfaction with pre-anaesthesia information about the procedure was low, 36\%. As was elucidated to in another study, the labor pains can alter concentration on the information being given thus altering the understanding and appreciation of the same altogether. However in the current study, over $50 \%$ of the respondents report no pre-anaesthesia visit by the anaesthesia team and could explain the dissatisfaction with the visit. Some studies have shown that the cause of discomfort from spinal anaesthesia are immobility of lower limbs, post operative nausea and vomiting, urine retention and headache (Bhattarai, Rahman, Sah, \& Singh, 2005).These post operative discomforts need to be communicated early enough to allay anxiety that can be occasioned by the experience post operatively. The poor quality of information depicted in this study is unfortunate as decision making about mode of birth presents challenges to women and requires a balance of risks and benefits according to individual circumstances. This opportunity is best provided by the medical personnel if the right information is communicated to the client. Informed decision making enhances women's power within the doctor-patient relationship resulting in increased maternal satisfaction (Shorten, Shorten, Keogh, West, \& Morris, 2005).

Despite advances in postoperative pain management, postoperative pain relief and satisfaction are still inadequate in some patients because of individual variability and limitation from side effects of analgesic drugs or techniques. Results from a study in the USA suggest that a patient has a 50 to $71 \%$ chance of experiencing moderate to severe pain after surgery (Apfelbaum, Chen, Mehta, \& Gan, 2003). In the current study, $47 \%$ of the clients experienced a disturbing backache postoperatively. However, there was no significant association between post operative pain and client satisfaction (OR: 0.76; 95\% CI: 0.25-2.28; P:0.62)

The current study also sought to establish the determinants of client satisfaction after spinal anaesthesia for CS. In the bivariate analysis the several factors demonstrated a significant relationship with patient satisfaction. Neonate's birth weight (OR: 3.29; 95\% CI: 1.01-10.71; P:0.04) and APGAR score at 10 minutes (OR:4.74; 95\% CI: 1.24-18.03; P:0.02) were significant parturition history aspects that showed significant relationship with maternal satisfaction (Sindhvananda, Leelanukrom, Rodanant, \& Sriprajittichai, 2004) An average birth weight of more than $3000 \mathrm{gm}$ and an APGAR score of 10 at 10 minutes were more than 3 times likely to lead to maternal satisfaction than a birth weight of less than 3000gm and APGAR score less than 10 in 10 minutes. This demonstrates that maternal satisfaction was more likely to be influenced by positive neonatal outcomes. The other unprecedented finding was that post operative visit was significant in determining patient satisfaction with care (OR: 3.29; 95\% CI: 1.24-18.03; P:0.04). Those who were not visited post operatively by the anaesthetist were more satisfied $(90 \%)$ with the anaesthesia care than those who were visited $(65 \%)$. This was explained by further analysis where fetal outcome was cross tabulated with postoperative visit. It was established that there was a significant relationship (OR: 0.12; 95\% CI: 0.12-0.56;P:0.008) between the outcome of the neonate and postoperative visit. This implies that most of the visits by the anaesthesia team were for those mothers who had neonates with non-reassuring status and thus likely that these mothers had the preponderance of not being satisfied with the aneasthesia care as earlier alluded to, neonatal outcomes are a predictor of 
maternal satisfaction. Other studies have demonstrated a positive effect of the visit by anaesthesia practitioner ((Melese et al., 2014; Sindhvananda et al., 2004)). Some studies did not elucidate any relationship between post operative visit and maternal satisfaction with care (Gebremedhn \& Nagaratnam, 2014)

\section{Conclusion}

Maternal satisfaction with anaesthesia care in the current study was $85 \%$ which is very low in comparison to other recorded levels of maternal satisfaction elsewhere. Dissatisfaction is most likely due to unmet maternal expectations. Researching patient satisfaction is important in understanding the problems which patients experience from spinal anaesthesia, and this can go a long way in helping improve the quality of anaesthesia and healthcare. Ensuring good quality of spinal anaesthesia and improving clinical skill of anaesthesia practitioners might improve patient satisfaction rate.

\section{Teaching institution and hospital}

\section{Recommendations}

1. More emphasis should be put on clinical communication skills of the anaesthesia practioners to improve quality of care for the clients.

2. Qualitative research into client's perceptions toward spinal anaesthesia for caesarean section should be carried out.

3. The hospital should carry out an exit interview for anaesthesia clients to help in management decisions

\section{Clients}

1. Clients should take active role in making choice of anaesthesia they prefer after getting information from the anaesthesia practioners.

\section{Anaesthesia practitioners}

1. Quality of pre and post operative visit by the anaesthesia teams should be deliberate with specific objectives for quality services improvement

2. More time should be given to client concern and complains by the anaesthesia team

\section{Reference}

[1]. Apfelbaum, J. L., Chen, C., Mehta, S. S., \& Gan, T. J. (2003). Postoperative Pain Experience: Results from a National Survey Suggest Postoperative Pain Continues to Be Undermanaged. http://doi.org/10.1213/01.ANE.0000068822.10113.9E

[2]. Bhattarai, B., Rahman, T. R., Sah, B. P., \& Singh, S. N. (2005). Central neural blocks: a quality assessment of anaesthesia in gynaecological surgeries. Nepal Medical College Journal : NMCJ, 7(2), 93-96.

[3]. Casey, W. F. (2000). Spinal Anaesthesia - a Practical Guide The Advantages of Spinal Anaesthesia Disadvantages of Spinal Anaesthesia. Update in Anaesthesia, 12(12), 1-7. Retrieved from http://www.nda.ox.ac.uk/wfsa/html/u12/u1208_01.htm

[4]. Dharmalingam, T. K., \& Ahmad Zainuddin, N. A. (2013). Survey on maternal satisfaction in receiving spinal anaesthesia for caesarean section. The Malaysian Journal of Medical Sciences: MJMS, 20(3), 51-4. Retrieved from http://www.pubmedcentral. nih.gov/articlerender.fcgi?artid=3743982\&tool=pmcentrez\&rendertype=abstract

[5]. Gebremedhn, E. G., \& Nagaratnam, V. (2014). Assessment of patient satisfaction with the preoperative anesthetic evaluation. Patient Related Outcome Measures, 5, 105-10. http://doi.org/10.2147/PROM.S66737

[6]. Melese, T., Gebrehiwot, Y., Bisetegne, D., \& Habte, D. (2014). Assessment of client satisfaction in labor and delivery services at a maternity referral hospital in Ethiopia. Pan African Medical Journal, 17. http://doi.org/10.11604/pamj.2014.17.76.3189

[7]. Rashad Siddiqi, \& Syed Asadullah Jafri. (2009). Maternal Satisfaction after Spinal Anaesthesia for Caesarean Deliveries. Journal of The College of Physicians and Surgeons Pakistan, 19(2), 77-80. Retrieved from http://www.jcpsp.pk/archive/2009/Feb2009/03.pdf

[8]. Shorten, A., Shorten, B., Keogh, J., West, S., \& Morris, J. (2005). Making Choices for Childbirth: ispp:A Randomized Controlled Trial of a Decision-aid for Informed Birth after Cesareana. Birth-Issues in Perinatal Care, 32(4), $252-261$. http://doi.org/10.1111/j.0730-7659.2005.00383.x

[9]. Sindhvananda, W., Leelanukrom, R., Rodanant, O., \& Sriprajittichai, P. (2004). Maternal satisfaction to epidural and spinal anesthesia for cesarean section. Journal of the Medical Association of Thailand = Chotmaihet Thangphaet, 87(6), 628-635.

[10]. South Australian Patient Evaluation of Health Services (PEHS). (2007). Maternity Services in South Australian Public Hospitals: Patient Satisfaction Survey Report. Retrieved from https://health.adelaide. edu.au/pros/docs/ reports/general/ maternal_child_health_pehs_maternity_report.pdf

[11]. Stanton, C. K., \& Holtz, S. A. (2006). Levels and trends in cesarean birth in the developing world. Studies in Family Planning, 37(1), 41-48. http://doi.org/10.1111/j.1728-4465.2006.00082.x

[12]. Van Campen, C., Sixma, H., Friele, R., Kerssens, J., Peters, L., \& Netherlands Institute of Primary Health Care. (1995). Quality of care and patient satisfaction: a review of measuring instruments. Medical Care Research and Review, 52(1), 109-133.

[13]. WHO. (2012). World Health statistics 2012. Retrieved from http://www.who.int/gho/publications/world_health_statistics/2012/en/ 